\title{
Strut reaction forces on a diaphragm wall: Comparison of numerical models, traditional methods and field measurements.
}

\section{Reacción de puntales en muro pantalla: Comparación entre modelos numéricos, métodos tradicionales y mediciones en terreno.}

Dennis Raddatz (Main and Contact Author)

Ferrara, Proyectos Especiales

Rengo 1270, Ñuñoa, Santiago, Chile, Tel: 56-994933035; Fax: 56-2-22041010

dennis.raddatz@ferrara.cl

Gonzalo Suazo

Universidad Técnica Federico Santa María, Depto. Obras Civiles

gonzalo.suazo@usm.cl

Oscar Taiba

Ferrara, Proyectos Especiales

oscartaiba@ferrara.cl

Manuscript Code: 492

Date of Acceptance/Reception: 01.08.2016/20.10.2014

\section{Abstract}

This research describes the technique of diaphragm wall as a retaining solution and the calculation methods for the reaction forces of struts used for supporting a wall. In addition, the procedure to obtain earth pressure values on the wall and their distribution under the Chilean Norm NCh.3206 and the German recommendation EAB are indicated. The structural elements and the geotechnical characterization of a strutted diaphragm wall with struts on three levels, built in the region of Valparaíso, Chile, are studied in order to obtain the strut reaction forces by using analytical and numerical models. Finally, results are shown, comparing the data recorded in-situ and values obtained through theoretical and numerical modeling for strut reaction forces.

Keywords: diaphragm wall; lateral earth pressure; pressure redistribution; struts; numerical modelling

Resumen

En este trabajo de investigación se describe la técnica de muro pantalla como solución de entibación y los métodos de cálculo para la reacción de los puntales que arriostran el muro. Además se indica el procedimiento para obtener los empujes de suelo sobre el muro y su redistribución según la norma chilena NCh.3206 y la recomendación alemana EAB. Se realiza el estudio de los elementos estructurales y de la caracterización geotécnica de un muro pantalla apuntalado en tres niveles y construido en la región de Valparaíso en Chile, con el objetivo de obtener la reacción en los puntales usando modelos analíticos y numéricos. Finalmente se entregan los resultados, comparando los datos registrados en terreno para la reacción de los puntales con los resultados de reacción obtenidos con los modelos teóricos y numéricos.

Palabras claves: muro pantalla; empuje lateral de suelo; redistribución de empujes; puntales; modelos numéricos

Introduction

Retaining structures are necessary when it is required to keep two different surface levels, one immediately next to the other (Coduto, Yeung \& Kitch, 2011). There are different types of retaining walls (Candogan, 2009), which are designed according to the magnitude of the earth pressure and the reaction forces generated along the structure to keep the state of balance. One type of retaining structure is the diaphragm wall, which consists of a continuous reinforced concrete wall built from the ground surface prior to the excavation. The struts can be used as bracing elements in the wall in order to reduce the shear forces and bending moments.

The following should be defined during the design stage of struts and diaphragm walls: the type of earth pressure acting on the wall, the pressure distribution on the wall, and the calculation method to estimate the reaction forces of the struts. The methods to calculate the reaction forces of struts (e.g. method of tributary areas) are described in this article and the recommendations to obtain the pressures on diaphragm walls are studied. Also, pressure distribution to be adopted according to Chilean Norm NCh3206 (INN, 2010) and the German recommendation EAB (Weissenbach, 2003) is also indicated.

After a study of the geotechnical parameters of the ground and the structural characteristics of diaphragm walls and struts, the different methods described are applied to the case of a diaphragm wall of Merval Stage IV project, in the 
city of Viña del Mar, Valparaíso region, from which load measurements were performed for the final stage of the excavation in the three rows of struts. Measurements of reactions on struts were performed using vibrating wire method. Each instrumented strut had a vibrating wire on their neutral axis (Errázuriz, 2008). Both reaction force values in the struts, registered in-situ and the reaction force results obtained by traditional methods for a static condition (excluding the pressure from earthquakes), are compared graphically with the results of reaction forces of a numerical model obtained by using the software of finite elements Plaxis 2D.

\section{Description of the Diaphragm Wall System}

The procedure of the diaphragm wall system has its origin in the 1950s in Italy (Schneebeli, 1981). The diaphragm wall is a continuous rectangular reinforced concrete wall of constant thickness, built from the ground surface. Excavated trench is performed in the primary panels in the first place (Stocker \& Waltz, 2003), and the support for the narrow trench occurs continuously with the aid of bentonite mud. After reaching the desired depth, the steel cage is installed and concrete pouring is started through a tremie pipe into the trench. This process is repeated in the secondary panels in order to achieve the continuity of the wall.

Diaphragm walls are used especially when a quick solution is required (Stocker \& Waltz, 2003), which generates low deformation during the excavation in front of them and zero vibrations occur during the building process, thus avoiding structural damage to structures near the project site. In addition, the diaphragm wall serves as a water barrier to groundwater flow, making it the ideal solution when having high stresses on the wall and when groundwater tables are present. Usually, a diaphragm wall is more expensive than other types of support structures, such as soldier pile walls or sheet pile walls, which are also used as solutions when groundwater tables are present (Weissenbach, Hettler \& Simpson, 2003). The diaphragm wall is economically desirable only when the wall being built with this technique to hold the soil during the excavation corresponds to the final perimeter wall of the projected structure.

Once the wall is built, the excavation can be started in front of it. The stability of the wall-ground system is maintained due to the passive pressure generated in the wall embedment area. In cases which there are large excavation depths, the internal forces generated on the wall make its construction infeasible without considering other supports at the length of the wall (González, 2001). In this case, the supports correspond to elements capable of restricting the deformations on the wall and resist the loads transmitted from the wall. Some support elements are: active anchors, passive anchors, shores or struts. The way in which these elements operate is different. The shores or struts operate by reacting on the ground or on the other side of the wall, and the anchors transmit the load to the ground through the ground-anchor interaction produced in the fixed length. Some recommendations, such as the ones given in the Technical Building Code of Spain, suggest the use of supports on the wall when excavation heights exceed 3 or $4 \mathrm{~m}$ of depth, or when there are structures close to the excavation (Sanhueza, 2009).

Constructing a retaining wall is difficult when the project is located in an urban area, due to the sets of underground services existing in the city, such as water, sewerage, electricity, optical fiber or gas, as well as building foundations or walls close to the excavation site (Gould, Tamaro \& Powers, 1992). The advantage of using struts instead of anchors is that direct interferences with the different underground services or surrounding structures are avoided, since the support system is completely in front of the wall. The disadvantage of using struts is the interference generated with equipment and personnel at work, slowing the excavation and construction processes of the different structures considered in the project.

In structures in contact with the ground, lateral earth pressure is a key element in the design (Bowles, 1996). For the specific case of retaining walls, a quantitative estimate of the lateral pressure is needed. With this, it is possible to identify the stresses on the wall and on the support points, which will allow the subsequent sizing and design.

Merval IV Stage Diaphragm Walls

\section{Diaphragm Wall Details}

The system most often used as support for deep temporary excavations of gravel soils from Santiago is the hand-dug piles, anchored and located discontinuously (Saez \& Ledezma, 2012). In recent years, anchored bored piles (executed with machine) have been used, serving the same function as hand-dug piles. This type of solution is repeated in other cities that have similar solid ground and when the groundwater table level is under the foundation level of the projected structure. Unlike the city of Santiago, on the flat part of Viña del Mar (coastal city at 100km from Santiago), 
groundwater table is found near the surface, and the soil is commonly sandy which increase its compactness with depth. Hence, the diaphragm wall is a solution often used in the area.

In the modernization and improvement process of the railway service between the cities of Valparaíso and Limache (Pilotes Terratest, n.d.a), an extension of $5 \mathrm{~km}$ of underground tunnel was considered for the train to pass beneath the downtown of Viña del Mar. As a solution to support the excavation, the implementation of diaphragm walls on both sides of the excavation was planned by the consortium of companies Pilotes Terratest S.A. and Soletanche Bachy Chile. The aforementioned walls were $60 \mathrm{~cm}$ thick, with heights of up to $21.50 \mathrm{~m}$, in panels $6.8 \mathrm{~m}$ long. As a support method, concrete struts of circular section were used, which reacted against the diaphragm walls at the front, as shown in the following figure.

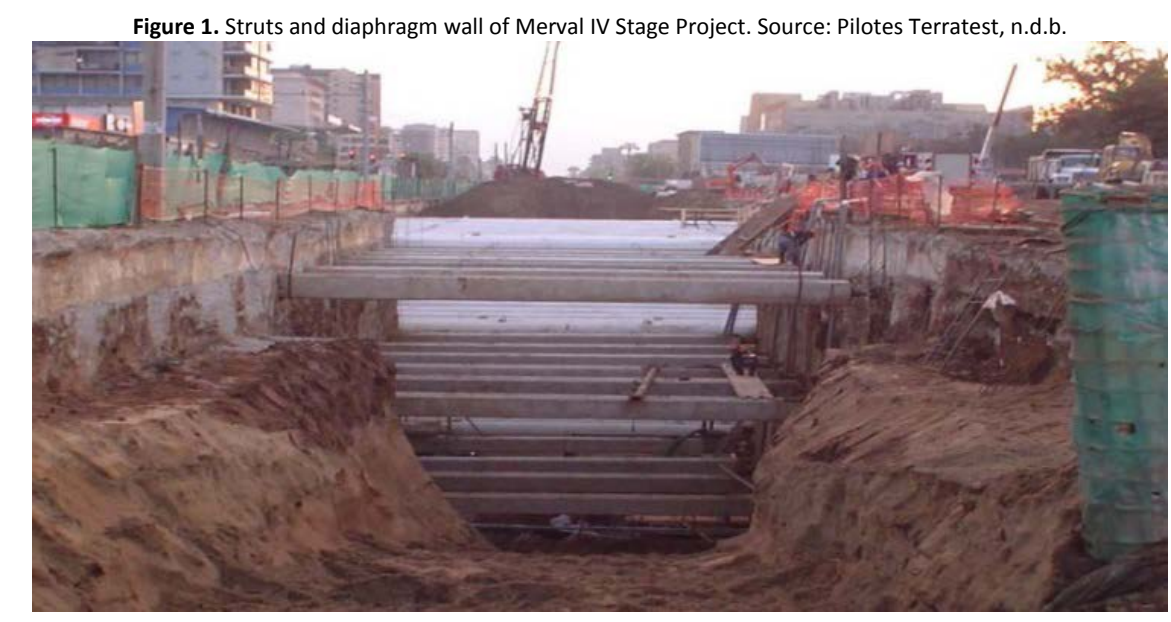

The length of the struts is dependent on the distance between the walls on both sides of the excavation. In the area where instrumentation was used to measure the load on the struts, the wall had an embedment of $7.50 \mathrm{~m}$ and a total height of $21.50 \mathrm{~m}$ (Errázuriz, 2008). Meanwhile, the struts at the instrumented section were made of reinforced concrete of an area of $1225 \mathrm{~cm} 2,10 \mathrm{~m}$ long and located in three rows on deep levels: $-1.50,-5.20$ and $-9.75 \mathrm{~m}$ in relation to the ground level. The horizontal distance between the centers of the struts was $3.40 \mathrm{~m}$.

Figure 2. Schematic representation of the studied case. Prepared by the authors, 2016.
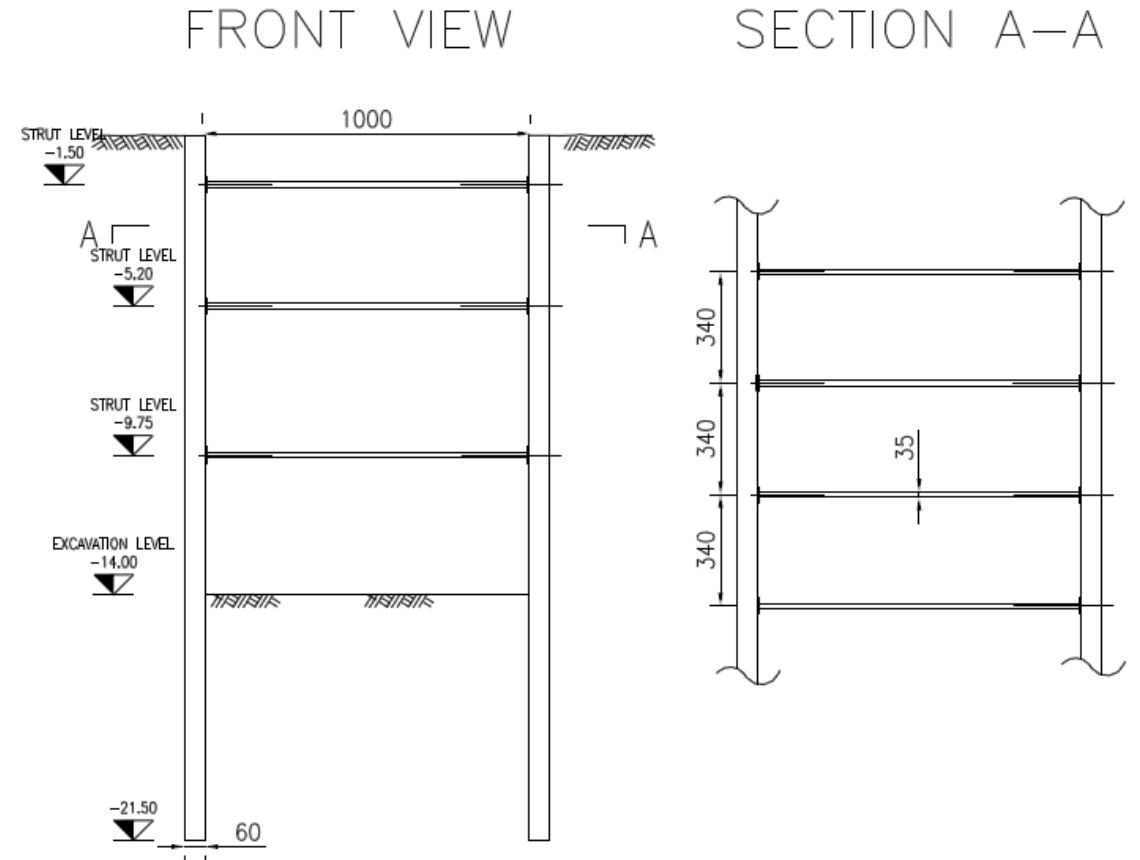


\section{Geotechnical Characterization}

Displayed geotechnical parameters correspond to the results of the studies performed by PETRUS Ingenieros Consultores S.A. (Errázuriz, 2008). The soil horizons have the following characteristics:

- Soil horizon U-1 (0.00 to -2.50): artificial backfill, consisting of sand with a high percentage of fine particles (from 15 to $45 \%)$.

- $\quad$ Soil horizon U-2 (-2.50 to -5.00): Medium sand with some silty fine particles, medium-high density.

- Soil horizon U-2B (-5.00 to -15.00): Medium sand with some silty fine particles, high density. Phreatic level at -6.50 m.

- Soil horizon U-2C (-15.00 to -20.00): Sand similar to soil horizon U-2B with a very high density, with numbers of blows over 50 for the Standard Penetration Test.

- Soil horizon U-4 (-20.00 to -25.00): weathered granodiorite, commonly known as maicillo. The shear-resistant parameters indicated in the below table were obtained experimentally (standard triaxial test) for the soil horizons defined above:

Table 1. Soil parameters. Errázuriz, 2008.

\begin{tabular}{|c|c|c|c|}
\hline \multirow{2}{*}{ Table 1. Soil parameters. Errázuriz, 2008.} \\
\cline { 3 - 4 } Soil Horizon & \multirow{2}{*}{ Condition } & \multicolumn{2}{|c|}{ Design Parameters } \\
\cline { 3 - 4 } & & $\mathbf{\circ}]$ & $\mathbf{C}\left[\mathrm{KN} / \mathbf{m}^{\mathbf{2}}\right]$ \\
\hline U-1 & Moist & 38 & 0 \\
\hline U-2A & Moist & 40 & 0 \\
\hline U-2B & Moist & 40 & 0 \\
\hline U-2B & Saturated & 43 & 0 \\
\hline U-2C & Saturated & 35 & 40 \\
\hline U-4 & Saturated & & \\
\hline
\end{tabular}

The following values for specific unit weights are used due to the density test results:

Table 2. Specific weights. Errázuriz, 2008.

\begin{tabular}{|c|c|}
\multicolumn{2}{|c|}{ Table 2. Specific weights. Errázuriz, 2008. } \\
\hline Condition & Specific weight $\left[\mathrm{KN} / \mathrm{m}^{3}\right]$ \\
\hline Moist & 18.00 \\
\hline Saturated & 21.00 \\
\hline Submerged & 11.00 \\
\hline
\end{tabular}

The following expressions for estimating the deformation modulus according to soil horizons and depth from the surface (z), were also included in performed soil studies:

\begin{tabular}{|c|c|c|}
\hline Soil horizon & $\mathrm{E}\left[\mathrm{KN} / \mathrm{m}^{2}\right]$ & Average Value $\left[\mathrm{KN} / \mathrm{m}^{2}\right]$ \\
\hline U-1 & $7000 z$ & 8750 \\
\hline$U-2 A$ & $7000 z$ & 26250 \\
\hline U-2B & $25000+5800 z$ & 83000 \\
\hline $\mathrm{U}-2 \mathrm{C}$ & $35000+6750 z$ & 153125 \\
\hline U-4 & 150000 & 150000 \\
\hline
\end{tabular}

\section{Calculation Method: Pressure and Struts}

For the calculation of the static earth pressure, that means, without considering the pressure by earthquakes, a weighting between the active pressure (50\%) and at rest pressure $(50 \%)$ is considered. This weighting is recommended by Weissenbach and collaborators (2003), who suggest the use of a weighting between both pressures for structures designed with restricted deformations. In this case, the kinematic constraints (struts and wall embedment) restrict lateral movements avoiding development of active pressure. In the design of retaining structures, it is common that during the design stage of walls and bracing elements, the active pressure for a temporary condition and the pressure at rest for a permanent condition are considered. An example of this is found in the design of an anchored wall described in the work performed by Anderson (1998).

In this section, the pressure redistribution proposed in the German recommendation EAB (Weissenbach, 2003) and in the Chilean Norm NCh 3206 (INN, 2010) is described. Furthermore, the method of tributary area and the method of 
articulation are described to obtain the reaction forces in the struts, which are used to obtain theoretically the loads of diaphragm wall struts in Merval IV Stage.

\section{Pressure Calculation}

The pressure coefficient at rest $\left(k_{0}\right)$ is calculated when evaluating the Jaky formula and the active pressure coefficient $\left(k_{a}\right)$ is calculated by Coulomb formula (Cype, n.d.). For the value of earth pressure on the diaphragm wall at a depth $z$ from the surface, earth coefficient is between ka and k0 depending on the lateral displacement, Eq1:

$$
E=\left[\alpha * K_{0}+(1-\alpha) * K_{a}\right] * \gamma * Z
$$

With; $\alpha$ : If $\alpha=0.0$ the lateral displacement allows fully mobilization of active pressure and if $\alpha=1.0$ lateral displacement is null (at rest pressure); $\gamma$ : Unit weight of the soil. The moist unit weight is considered when performing the analysis above the level of the groundwater table, and the submerged unit weight when the analysis is performed below the groundwater table level; z: Depth measured from the surface. The weighting indicated above between active and at rest pressure is used $(\alpha=0.5)$ and the action of the hydrostatic pressure is considered, that is, the water pressure from the level of the groundwater table downwards.

\section{Pressure Distribution}

Since the wall has several support levels, it is necessary to study the redistribution of the pressures. In $E A B$ (Weissenbach, 2003), different pressure distributions are indicated; they depend on the wall type, the number of strut levels and their location. For the case of three levels of struts, redistribution is triangular from zero at the top of the wall until $\mathrm{e}_{\mathrm{h} 0}$ on the strut second level, it is considered constant $\left(\mathrm{e}_{\mathrm{h} 0}\right)$ between the second and third strut level, and trapezoidal from the third strut level $\left(\mathrm{e}_{\mathrm{h} 0}\right)$ to the final excavation level $\left(\mathrm{e}_{\mathrm{hu}}\right)$. In the case of in-situ concrete walls with three strut levels, the ratio $\mathrm{e}_{\mathrm{h} 0}: \mathrm{e}_{\mathrm{hu}}$ of $2: 1$ is indicated. Furthermore, Chilean Norm NCh 3206 (INN, 2010) only differentiates between the case with one support level and the case with more than one support level. For the case of more than one level, the uniform distribution can be used in the depth for the pressure. For both cases, the total earth pressure was calculated with equation (1) and redistributed as indicated above. The following figure shows the results obtained by using both distributions for diaphragm walls for Merval Stage IV project:

Figure 3. Pressure redistribution according to EAB (left) and NCh3206 (right). Prepared by the authors, 2013.

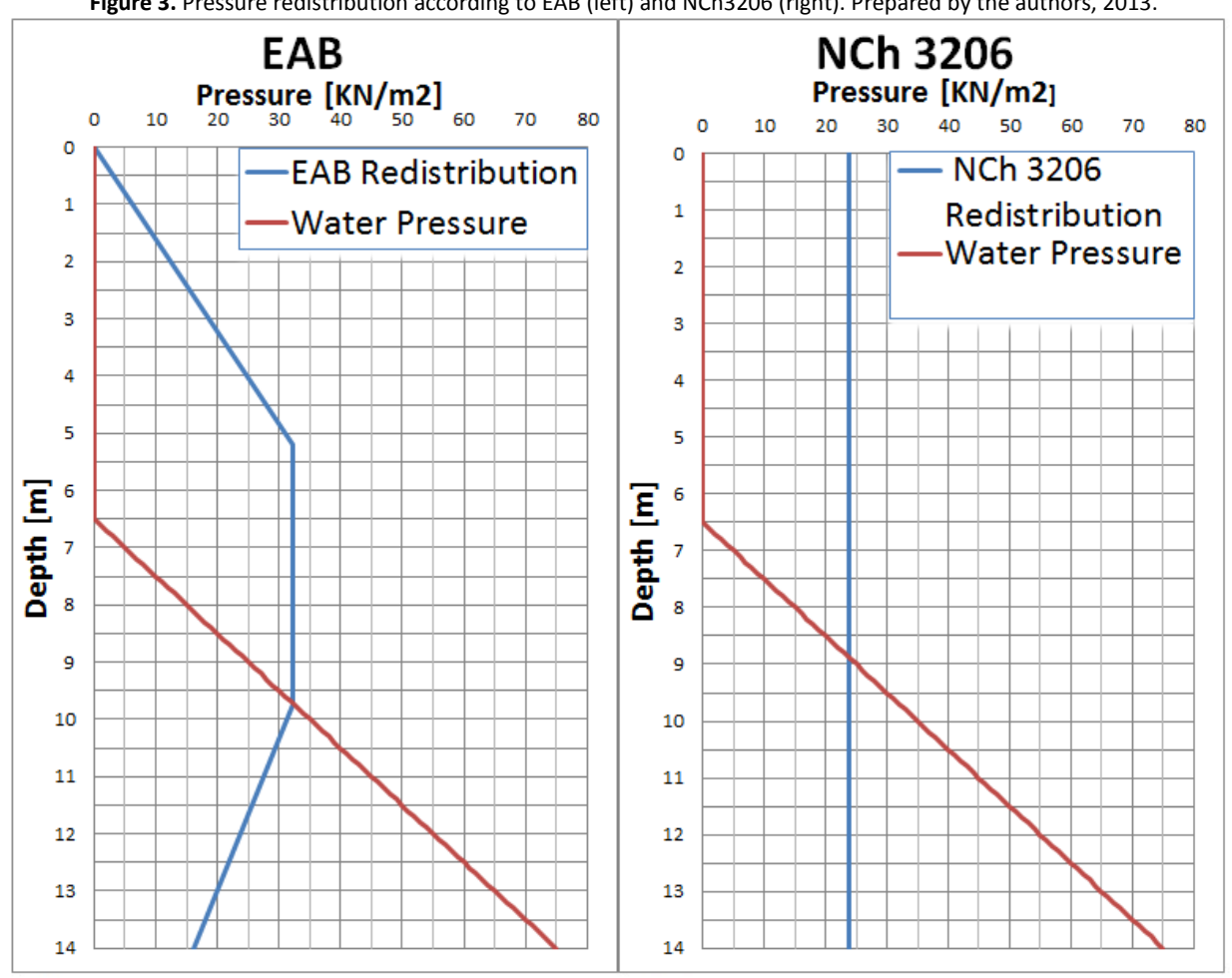




\section{Calculation of Reactions in Struts by the Method of Tributary Areas}

The load on the struts can be approximately determined by the method of tributary areas (Terzaghi, Peck \& Mesri, 1996), which consists on dividing in sections the pressure acting on the diaphragm wall. The division of these sections is performed in the middle of the distance between the struts, assigning the pressure value of each section to the strut that is in that section. This way, the first strut is assigned with the pressure between the Surface level $(z=0)$ until the depth $-3.35 \mathrm{~m}$, as reaction. For the second strut, the pressure between depths $-3.35 \mathrm{~m}$ and $-7.48 \mathrm{~m}$ are assigned. And for the third strut, the pressures between depths $-7.48 \mathrm{~m}$ and $-11.86 \mathrm{~m}$ are assigned. The horizontal distance between struts should be considered for the value of total strut reaction forces.

\section{Calculation of Reactions in Struts by the Articulation Method}

Another method to determine the reaction load in the struts is the method of articulation (Errázuriz, 2008), in which the pressure on the diaphragm wall is also divided into sections. With this method, the reaction on the struts is calculated by adding moment at the support points, and by adding the forces considering the pressures on the diaphragm wall and the strut reactions forces. The first section corresponds to the pressures from the surface $(z=0)$ to the level of the second strut $(-5.2 \mathrm{~m})$. From this analysis, the reaction in the first strut and a portion of the reaction of the second strut are obtained. The second section corresponds to the pressures from the level of the second strut ($5.2 \mathrm{~m})$ to the level of the third strut $(-9.75 \mathrm{~m})$. From this analysis, the missing reaction of the second strut and a portion of the reaction of the third strut are obtained. The third section corresponds to the pressures from the level of the third strut $(-9.75 \mathrm{~m})$ to the seal of the final excavation $(-14 \mathrm{~m})$. From this analysis, the missing reaction of the third strut is obtained. Also, the horizontal distance between struts should be considered for the value of total strut reaction forces.

\section{Analysis of Finite Elements}

In this section, the analysis performed by means of the software of finite elements, Plaxis 2D, is summarized. For modeling the case of the diaphragm wall of Merval IV Stage, the option of plane strain model was used due to the uniformity of the cross section. The diaphragm wall was modeled by means of plate-type elements and the struts were modeled using the option of node-to-node anchor, which allows the rotation around the diaphragm wall-strut junction point.

Figure 4. Plaxis 2D model. Prepared by the authors, 2013.

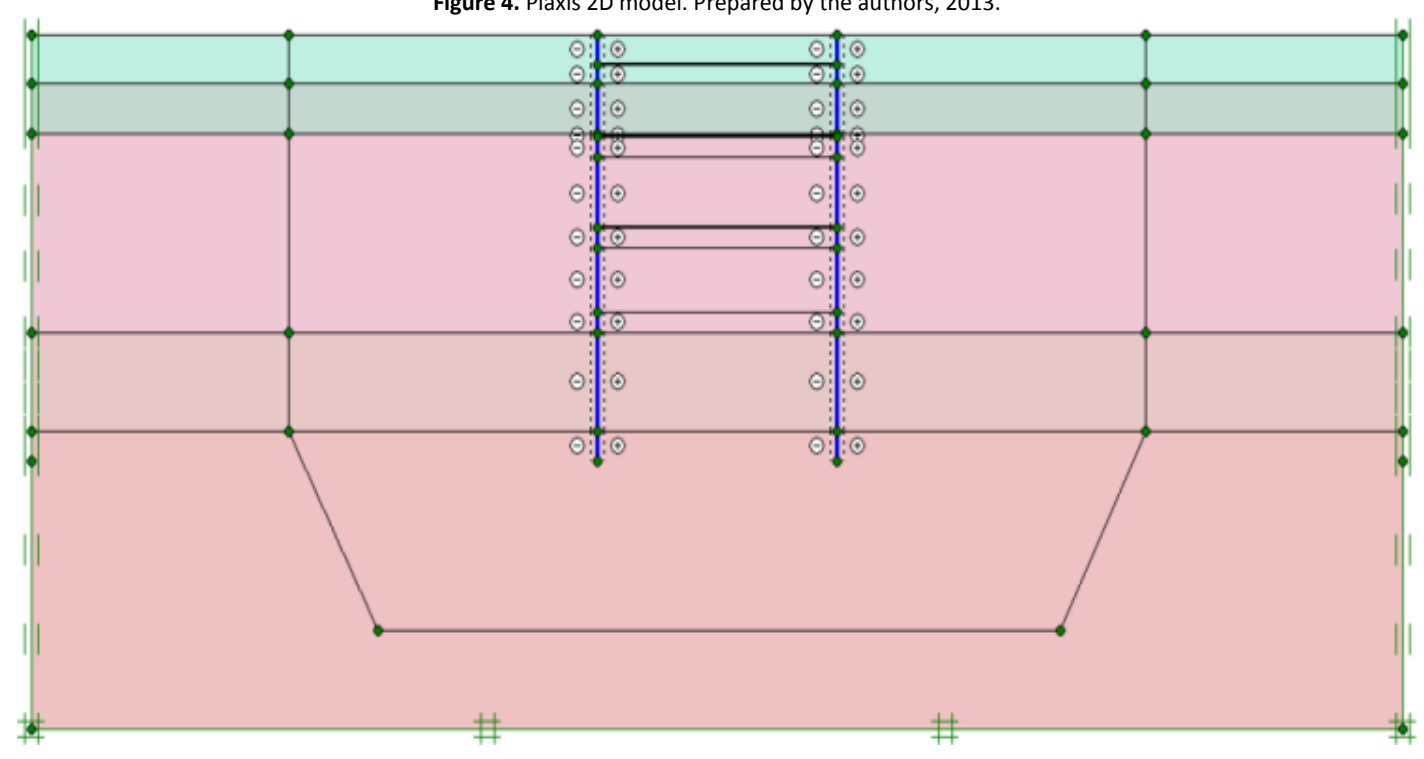

To model soil behavior, the hardening soil model was used, which includes hardening by compression to simulate the irreversible compaction of the soil under a primary compression (Brinkgreve, 2004). Some parameters required for modeling soil behavior with this model (Plaxis, 2004), are: triaxial loading stiffness $\left(E_{50}\right)$, oedometer load stiffness $\left(E_{\text {oed }}\right)$ and triaxial unloading stiffness $\left(E_{u r}\right)$. The following relationships between stiffness can be considered as approximate values: 


$$
E_{u r}=3 * E_{50}
$$

$$
E_{\text {oed }}=E_{50}
$$

In a simplified manner, $E_{50}$ was considered as the average value of the deformation modulus of each soil horizon. These values were previously shown in Table 3.

\section{Results}

The results theoretically obtained for the load on the struts were compared to the values measured in-situ on the instrumented struts for different sections and described in Errázuriz (2008). These comparisons are shown in the following figure:

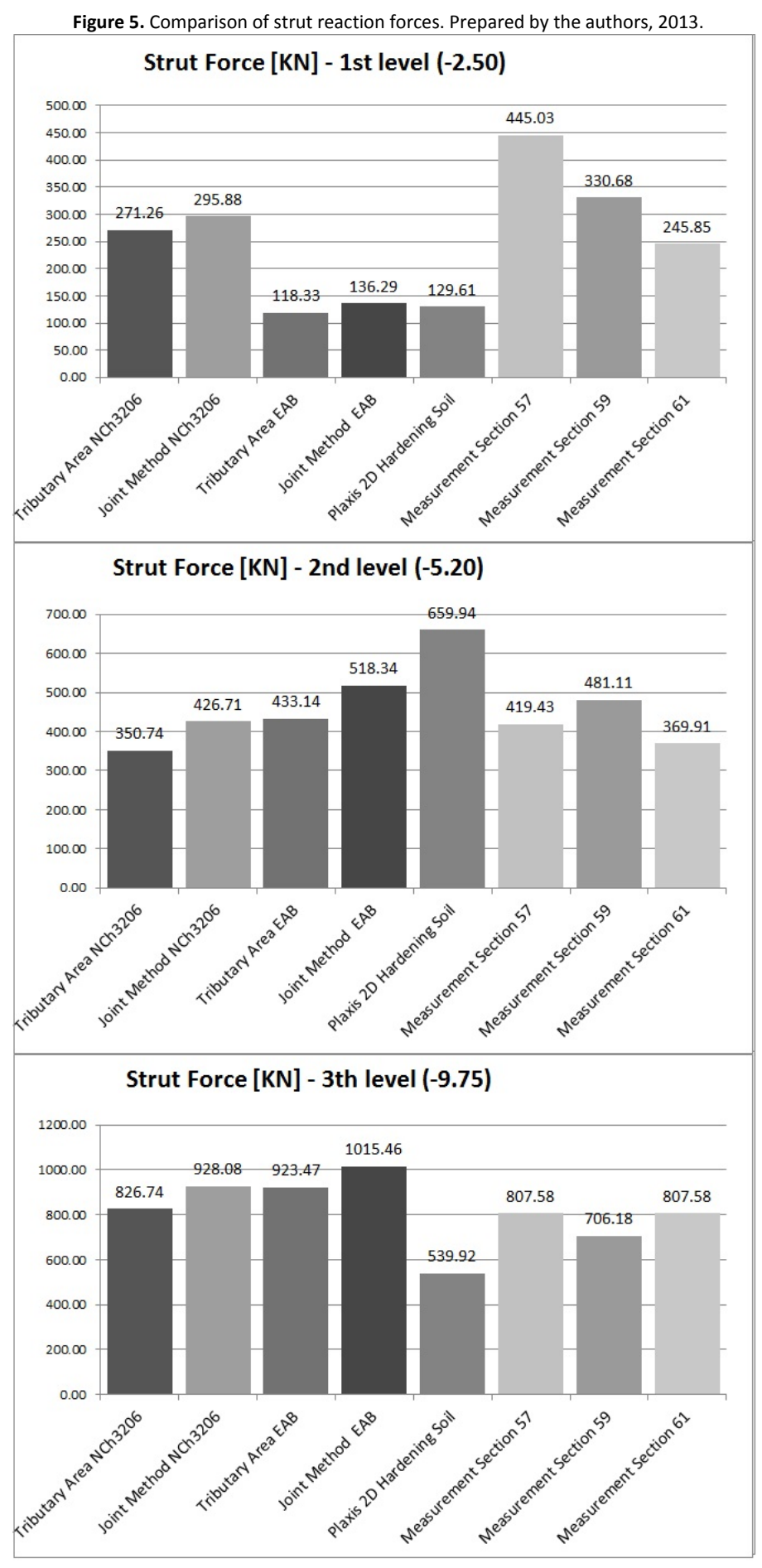


The difference between using different pressure redistributions becomes evident in the reaction value obtained for the first row of struts. With a uniform redistribution according to NCh 3206, the reaction value approximately twice the value obtained using the redistribution according to the German recommendation EAB. In the following two rows of struts there is no noticeable difference between the two types of redistribution. The results of the reaction on the struts obtained from the modeling through finite elements performed in software Plaxis 2D, are close to the reaction values in the struts that were measured in the second and third row of struts.

\section{Discussion and Conclusions}

The use of the weighting of $50 \%$ of active pressure and $50 \%$ of at rest pressure given by Weissenbach and collaborators (2003), delivers useful approximations of reaction values in the struts in relation to the values obtained in-situ. The addition of the reactions on the three struts obtained using this pressure weighting is similar to the addition of the reactions obtained on field, which validates the assumed condition of a partial development of the active pressure due to the wall embedment, and in particular, at the strut levels due to the stiffness of the struts.

In this case, the redistribution proposed by the Chilean Norm NCh3206 presents values closer to the ones measured in-situ for the first row of struts than the redistribution proposed by the German recommendation EAB. It should be noted that neither used redistribution make any differentiation on the type of soil, so an important variable may be missing in the analysis. Terzaghi and others (1996), propose a distribution of uniform pressures when in presence of sandy soil, and triangular at the highest part of the diaphragm wall when in presence of cohesive soils. The soil of the studied Project corresponds mainly to sand that increases in compactness with depth, so when applying the method proposed by Terzaghi, an uniform pressure redistribution should be considered as suggested by Chilean Norm NCh 3206.

The modeling performed using the software of finite elements Plaxis 2D, delivers results similar to those recorded in the instrumented struts of the second and third rows. Moreover, the addition of the reactions on the three rows is close to the addition of the reaction values recorded in-situ. The observed differences can be explained by the strength parameters assumed on the software, which do not necessarily represent the in-situ condition of the different soil horizons. It is not possible to discard potential disturbances in the measurements performed to the first row of struts, due to the pre-compression produced during the strut installation process, since the superficial pressures as the train running beside the diaphragm wall or due to that the first row of struts shows higher reaction values in stages prior to the final excavation state.

The pressure redistribution influences the design of the structural elements, so care should be taken in choosing one or the other method. Also, safety factors should be considered for the design of structural elements. When considering uniform-type distribution, the location of the strut will be closer to the surface so that the pressures generated in the wall and in the strut are not so high. For bending moments in the wall, the difference in considering one or other pressure distribution would be more noticeable, since besides the pressure, the location of the resultant from pressure has influence. Possible earthquake loads should be studied on the design stage, considering also how that extra pressure will affect the system (e.g. pressure diagram form). Just as important as the design and the construction of a project, the instrumentation must be also considered fundamental. In the studied case, the reaction force values measured on the struts are set, which are important to verify the considerations used in the design and the construction methods.

Acknowledgements

We would like to thank Pilotes Terratest for providing us with the background information on Merval Stage IV Diaphragm Wall Project, which allowed performing the theoretical and numerical models presented in this research article. 
Anderson, T. C. (1998). Anchored deep soil mixed cutoff/retaining walls for lake parkway project in Milwaukee, Wisconsin. In J. Finno, Y. Hashash, C. Ho, \& B. P. Sweeney (Eds.), Design and construction of earth retaining systems (pp. 1-13). Reston, VA: ASCE.

Bowles, J. E. (1996). Foundation analysis and design. New York: MacGraw-Hill.

Brinkgreve, R. B. J. (2004). Reference manual. Delft: Delft University of Technology and Plaxis BV.

Candogan, A. (2009). The art and practice of foundation engineering. Istanbul: Ali Candogan.

Coduto, D. P., M.R., Y., \& Kitch, W. A. (2011). Geotechnical engineering: Principles and practices. New York: Pearson Education.

Errázuriz, E. (2008). Pantallas de contención: Métodos de diseño y aplicaciones. Universidad de Chile.

González, M. (2001). El terreno. Barcelona: Ediciones UPC.

Gould, J., Tamaro, G., \& Powers, J. (1992). Excavation and support systems in urban settings. In T. D. O’Rourke \& A. G. Hobelman (Eds.), Excavation and support for the urban infrastructure (pp. 144-171). New York: ASCE.

CYPE Ingenieros (n.d.), Elementos de contención: cálculo de empujes. Alicante: Cype Ingenieros S.A. website on 01.03.2014

INN. (2010). NCh 3206 Of. 2010: Geotecnia - excavaciones, entibaciones y socalzados - requisitos. Santiago: Instituto Nacional de Normalización.

Plaxis. (2004). Materials models manual. Delft: Delft University of Technology and Plaxis BV.

Sáez, E., \& Ledezma, C. (2012). Earthquake-induced pressures on discontinuous piling support on Santiago gravel. Soil Dynamics and Earthquake Engineering, 41, 72-83. http://doi.org/10.1016/j.soildyn.2012.05.007

Sanhueza, C. (2009). Influencia de la cohesión sobre los movimientos de un muro pantalla y su profundidad de empotramiento. Revista de La Construcción, 8(1), 126-133.

Schneebeli, G. (1981). Muros pantallas: Técnicas de realización, métodos de cálculo. Barcelona: Editores técnicos asociados.

Stocker, M., \& Waltz, B. (2003). Bored pile walls, diaphragm walls, cut-off walls. In U. Smoltczyk (Ed.), Geotechnical engineering handbook volume 3: Elements and structures (pp. 273-407). Berlin: Ernst and Sohn.

Terratest, P. (n.d.-a). Inyecciones: Proyecto Merval IV etapa. Retrieved from http://www.terratest.cl/documentos/FT-00592-02-rev

Terratest, P. (n.d.-b). Muro pantalla: Proyecto Merval IV etapa. Retrieved from http://www.terratest.cl/documentos/FT-00592-01-rev3.pdf 